\title{
AN ANALYSIS OF THE COMPLETENESS OF REFERRAL FORMS AND CASES EVALUATED BY AN ORAL MEDICINE SPECIALIZED SERVICE
}

\author{
Bianca Dutra Guzenski ${ }^{1}$, Thiago Tomazetti Casotti ${ }^{1}$, Jessica Rodriguez Strey ${ }^{1}$, \\ Manoela Domingues Martins ${ }^{1}$, Pantelis Varvaki Rados ${ }^{1}$, Vinicius Coelho Carrard ${ }^{1}$
}

\begin{abstract}
Introduction: Oral lesions are present in approximately $30 \%$ of the population worldwide. Although the mouth is an anatomical region that can be easily accessed for direct visual examination, most dentists of dental surgeons have reported difficulties in the diagnosis and management of oral diseases. The primary aim of this study was to assess the completeness of referral forms of the patients referred by dentists from the primary care basic health units to an Oral Medicine service. The secondary aim was to analyze if the complexity of the cases justify the referral to a specialist.
\end{abstract}

Methods: Data from 131 referral forms of patients referred from June 2014 to April 2016 were retrieved from the records. The referral's completeness analysis comprised two stages. Stage 1 mainly comprised patient and applicant's information. In the Stage 2, the documents were scored according to amount of information, including the description of the lesion characteristics and the procedures required for the patients' diagnosis and management. The referral was considered justifiable if some procedures not available at primary care were required for diagnosis or treatment.

Results: Five (9.8\%) referral forms were considered well filled. Diagnosis agreement was $71.4 \%$. Regarding the need of referral, $40,6 \%$ of the cases $(n=50)$ could be settle at the primary care.

Conclusion: In conclusion, few referral forms had high-quality information and the many cases could be managed at primary care health services.

Keywords: Referral and consultation; Primary healthcare; Dentistry; Oral medicine; Public health

\section{INTRODUCTION}

Oral lesions are present in approximately one-third of the population worldwide ${ }^{1-3}$. The buccal cavity is an anatomical region that can be easily accessed for direct visual examination 4 . However, $85 \%$ of dental surgeons have reported difficulties in the diagnosis and management of oral diseases ${ }^{5}$. This is partly because of either the lack of practice during the training period or the lack of interest in seeking activities to update their knowledge and skills this area ${ }^{5-8}$. Consequently, large numbers of patients are referred to specialists for consultation.

The Brazilian Unified Health System (SUS) is based on healthcare units with different levels of complexity. The patients' flow through the different levels is coordinated by a network of services, aiming to guarantee their access to comprehensive and continuous healthcare. In this system, the primary level represents the first contact of the population with the healthcare system. It is assumed that cases requiring more sophisticated resources and/ or the evaluation of specialists might be referred to specialized services that are characterized for secondary care. This flow requires filling out a document with information about the case, which is known as the referral form ${ }^{9-13}$.
Clin Biomed Res. 2021;41(4):283-290

1 Patologia bucal, Departamento de Odontologia Conservadora, Faculdade de Odontologia, Universidade Federal do Rio Grande do Sul. Porto Alegre, RS. Brasil.

Corresponding author: Vinicius Coelho Carrard vccarrard@gmail.com Departamento de Odontologia Conservadora, Faculdade de Odontologia, Universidade Federal do Rio Grande do Sul

Rua Ramiro Barcelos, 2492/503 90035-003, Porto Alegre, RS, Brasil. 
Even though no consensus exists regarding the amount of information required for an ideal referral form, the basic content includes information on the professional, the patient, and the characteristics of the lesion in question ${ }^{14}$. Several studies have shown that the information available in these documents is of poor quality, which hampers the agility and problem-solving capacity of the specialized services $^{15-19}$. Therefore, the primary objective of this study was to analyze the completeness of the referral forms pertaining to the cases referred to a dental specialty center in the southern region of Brazil. The secondary objective was to analyze the types of cases referred and evaluate whether their complexity justified the assessment by a specialist.

\section{METHODS}

\section{Study design and sample}

This cross-sectional analytical study accounted with referral forms of patients referred to Oral Medicine specialized center of our Institution. This specialized service is one of the 5 secondary care units that receives patients from the primary health care in Porto Alegre, the capital of Rio Grande do Sul State (Southernmost State of Brazil). The primary health care is the first line of public health services and is comprised by approximately 133 health basic units distributed along the municipality.

The sample was collected from the patient's records in the database of the dental specialties center based in Federal University of Rio Grande do Sul. This convenience sample comprised all referral forms from June 2014 to April $2016(n=174)$ and the respective patient records were collected for analysis. To date, the number of referrals to that service ranges from 10 to 17 by month. Data related to the referral forms were retrieved and entered a database. The present study protocol was submitted to and approved by the local Research Committee (protocol no. 18.980).

\section{Classification criteria}

\section{Analysis of the completeness of referral forms}

The criteria to define the referral forms as complete or incomplete were based on previous studies ${ }^{14,20,21}$. The analysis of the completeness of the referral forms comprised two stages:

Stage 1 consisted of personal data of the requesting professional and the patient (name and address), reason for referral or main complaint, legibility of the letter and the date of referral. At this point, all information should be present for the document to go to Stage 2 of analysis. Unlike the studies that supported this methodology, the telephone number and the email address of the applicant were not considered because their low frequency would compromise the transition of most referral forms to Stage 2.

Stage 2 consisted of additional patient data and lesion characteristics, to which points were attributed as follows: age of the patient (1 point), patient's telephone number ( 1 point), risk factors (2 points), previous treatments (1 point), description of the lesion (color, site, elementary lesion, size, texture/surface, margin; 1 point each). The document that scored 5 points or more was considered adequately filled. Medical history, diagnostic hypothesis, time of lesion progression, habits, and complementary exams performed before the referral, and need for urgency were considered additional information and did not add points.

\section{Analysis of care records}

The cases referred were analyzed using the information retrieved from the patient care records. Information such as waiting time for care, time of lesion progression that justified the referral and clinical diagnosis suggested by the team of specialists were recorded. In addition, the agreement between the clinical diagnosis of the primary care professional and the clinical diagnosis of the specialist was evaluated.

Subsequently, it was evaluated if the degree of complexity of the cases justified the referral or if its management would have been possible in the primary care. This analysis was based on the type of procedure required to establish the diagnosis or to manage the condition, because radiographic examinations, biopsies and other surgical procedures, or some treatments such as sclerotherapy are not offered in primary care and at diagnosis, taking into account that some benign diseases can be treated by the general dental surgeon and that variations from the normal pattern do not characterize diseases.

\section{Statistical analysis}

The categorical variables were described as absolute frequency and percentage relative frequency. The software used for statistical analysis was PASW version 18.0 .

\section{RESULTS}

A total of 131 referral forms and corresponding care records were analyzed. The mean age of the patients was $48.2 \pm 19.9$ years, ranging from 0 to 84 years. Most patients referred were female $(n=97$, $73.5 \%$ ). Forty-three referral forms were excluded from the final sample of this study because of the patients' non-attendance for appointments.

\section{Analysis of referral form completeness}

Table 1 shows the frequency of all information concerning Stage 1 in the referral forms. Most of the 
personal data was well filled. The data with the highest percentage of presence was the patient's name $(n=131,100.0 \%)$, whereas the data with the lowest percentage was the reason for referral obtained $(n=68$, $51.9 \%)$. A total of 51 forms (38.9\%) included all the items referring to Stage 1 and advanced to Stage 2 of the analysis.

Table 1: Frequency of data provided for Stage 1.

\begin{tabular}{lcc}
\hline \multicolumn{1}{c}{ Variable } & $\mathbf{n}$ & $\%$ \\
\hline $\begin{array}{l}\text { Patient name } \\
\text { Yes }\end{array}$ & 131 & 100.0 \\
$\quad$ No & 0 & 0.0 \\
$\begin{array}{l}\text { Patient address } \\
\text { Yes }\end{array}$ & 113 & 86.2 \\
$\quad$ No & 18 & 13.8 \\
$\begin{array}{l}\text { Name of the professional } \\
\text { Yes }\end{array}$ & 121 & 92.4 \\
$\quad$ No & 10 & 7.6 \\
$\begin{array}{l}\text { Address of the professional } \\
\text { Yes }\end{array}$ & 123 & 93.9 \\
$\quad$ No & 8 & 6.1 \\
Date & & \\
Yes & 128 & 97.7 \\
$\quad$ No & 3 & 2.3 \\
Main complaint & & \\
$\quad$ Yes & 68 & 51.9 \\
No & 63 & 48.1 \\
Legibility & & \\
Yes & 120 & 91.6 \\
No & 11 & 8.4 \\
\hline
\end{tabular}

The analysis of the data completeness of the referral forms in Stage 2 is presented in Table 2. Age and telephone number were the most frequently filled data $(n=51,100 \%)$ in the referral forms analyzed in this stage. Data regarding elementary lesions was found in less than half of the forms $(n=18,35.29 \%)$. Among the other characteristics of the lesions, location was the most described ( $n=48,94.1 \%)$ and the margin of the lesion was described in one referral form (2.0\%). Only $3.8 \%(n=5)$ of the analyzed referral forms contained sufficient data to be considered as well filled in Stage 2 . The separate evaluation of potentially malignant disorders and malignant lesions showed that 12 referrals out of 14 were poorly filled in Table 3. Of these, seven did not include a diagnostic hypothesis.

Table 2: Frequency of data analyzed in Stage 2.

\begin{tabular}{lcc}
\hline Variable & $\mathbf{n}$ & $\mathbf{\%}$ \\
\hline Patient age & & \\
Yes & 51 & 100.0 \\
No & 0 & 0.0 \\
Patient telephone number & & \\
Yes & 48 & 94.1 \\
No & 3 & 5.9 \\
\hline & & Continues...
\end{tabular}

Table 2: Continuation

\begin{tabular}{lcc}
\hline Variable & $\mathbf{n}$ & \% \\
\hline Risk factors & 9 & 17.6 \\
Yes & 42 & 82.4 \\
No & & \\
Previous treatments & 6 & 11.8 \\
Yes & 45 & 88.2 \\
No & & \\
Lesion description & & \\
Elementary lesion & 18 & 35.3 \\
Yes & 33 & 64.7 \\
No & & \\
Site & 49 & 96.1 \\
Yes & 2 & 3.9 \\
No & & \\
Color & 12 & 23.5 \\
Yes & 39 & 76.5 \\
No & & \\
Size & 7 & 13.7 \\
Yes & & 86.3 \\
No & & \\
Texture/surface & 44 & 13.7 \\
Yes & & 86.3 \\
No & 7 & 2.0 \\
Margin & & \\
Yes & & \\
No & 44.0 \\
\hline
\end{tabular}

Table 3: Summary of the evaluation of referral forms of potentially malignant and malignant cases and waiting time for care.

\begin{tabular}{lllc}
\hline Variable & $\begin{array}{c}\text { Completeness } \\
\text { of referral } \\
\text { form }\end{array}$ & $\begin{array}{c}\text { Clinical } \\
\text { impression }\end{array}$ & $\begin{array}{c}\text { Waiting } \\
\text { time for } \\
\text { care } \\
\text { (days) }\end{array}$ \\
\hline $\begin{array}{l}\text { Actinic cheilitis } \\
\text { Lichen planus }\end{array}$ & $\begin{array}{l}\text { Poor } \\
\text { Poor }\end{array}$ & $\begin{array}{l}\text { Right } \\
\text { Not } \\
\text { informed }\end{array}$ & 5 \\
& Poor & $\begin{array}{l}\text { Not } \\
\text { informed }\end{array}$ & 16 \\
& Poor & $\begin{array}{l}\text { Not } \\
\text { informed }\end{array}$ & 5 \\
& Poor & $\begin{array}{l}\text { Right } \\
\text { Right }\end{array}$ & 16 \\
& Poor & $\begin{array}{l}\text { Not } \\
\text { informed }\end{array}$ & 5 \\
Leukoplakia & Poor & $\begin{array}{l}\text { Not } \\
\text { informed }\end{array}$ & 11 \\
& Complete & $\begin{array}{l}\text { Not } \\
\text { informed }\end{array}$ & 16 \\
& Complete & $\begin{array}{l}\text { Not } \\
\text { informed }\end{array}$ & 7 \\
& Poor & $\begin{array}{l}\text { Right } \\
\text { Right } \\
\text { Not } \\
\text { informed } \\
\text { Not } \\
\text { informed }\end{array}$ & 12 \\
\hline Squamous cell \\
carcinoma
\end{tabular}




\section{Additional data}

We also recorded the frequency of some additional information that was not part of the criteria used for assessing the completeness of the forms. Twenty-five referral forms $(19.08 \%)$ contained the telephone number of the professionals responsible for the referral. In 123 cases $(93.89 \%)$, there was information regarding the professional category, with the majority of applicants $(n=120,97.56 \%)$ being dental surgeons. Physicians were responsible for three referrals $(2.43 \%)$. Regarding data obtained during the anamnesis, we observed that 28 forms $(22.1 \%)$ included the patient's medical history. The clinical impression or diagnostic hypothesis of the applicant was present in 64 referral forms $(48.9 \%)$. In addition, only one form $(0.76 \%)$ mentioned the requirement for urgent care.

\section{Analysis of dental records}

The analysis of the dental records showed an average waiting time for care of $13.8( \pm 34.6)$ days at the Dental Specialties Center. Information regarding the time of lesion progression was presenting $38(29.0 \%)$ of the referral forms, whereas the same information was provided in $84(64.12 \%)$ records. We observed that $65.4 \%$ of the patients had lesions in the mouth for more than two months. These data are depicted in Figure 1.

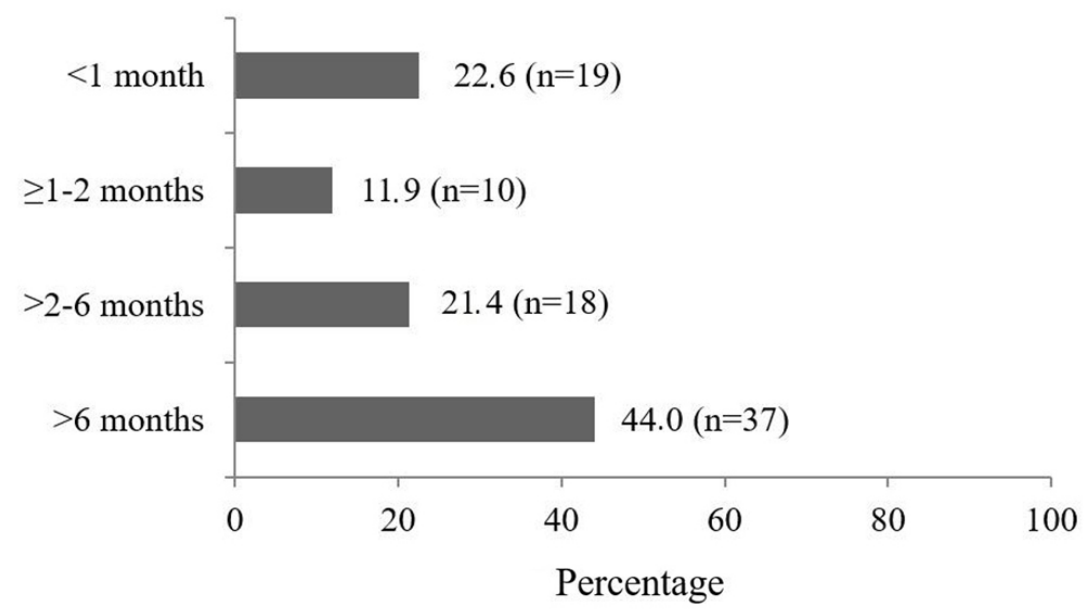

Figure 1: Time of lesion progression ( $n=84$, data not available $=47$ ).

The most frequent findings were as follows: non-neoplastic proliferative lesions (NNPP; $n=29$, $22.14 \%)$; no lesion/scar tissue $(n=9,6.9 \%)$; fibroma $(n=9,6.9 \%)$; recurrent aphthous ulcerations/traumatic ulcers $(n=7,5.3 \%)$; candidiasis $(n=6,4.5 \%)$; lichen planus $(n=6,4.5 \%)$; chronic nibbling/frictional keratosis $(n=5,3,8 \%)$; mucocele $(n=5,3.8 \%)$; and leukoplakia $(n=5,3.8 \%)$. In the study period, only one case $(0.8 \%)$ of squamous cell carcinoma was recorded. The NNPP included inflammatory hyperplasia $(n=24,18.3 \%)$; pyogenic granuloma $(n=2,1.5 \%)$; peripheral ossifying fibroma $(n=1$, $0.8 \%)$; and giant cell lesion $(n=2,1.5 \%)$.

The diagnostic concordance was calculated on the basis of $62(47.3 \%)$ referral forms in which the applicants had informed of their diagnostic impression. Among these, concordance was observed in 45 cases $(72.9 \%)$.

Patient referral was because of variations from the normal pattern $(n=8,6.1 \%)$ and problems not related to stomatology in two patients (one case of bruxism and one case of third molar extraction). The normality variations observed were as follows: four cases of torus/exostosis $(3.1 \%)$, two cases of varicosities $(1.5 \%)$, and two cases of Fordyce granules $(1.5 \%)$.

In addition, the analyses of the patients' records showed that 37 patients $(28.2 \%)$ had 47 lesions that had not been described in the referral forms. Among these, the most frequent lesions were candidiasis $(n=9,19.1 \%)$; inflammatory hyperplasia $(n=6$, $12.7 \%)$; actinic cheilitis ( $n=6,12.7 \%)$; traumatic lesion $(n=5,10.6 \%)$; and vascular change/ hemangioma $(n=4,8.5 \%)$. Notably, one patient $(2.1 \%)$ who demonstrated lichen planus did not have this information included in the referral form.

\section{Analysis of the requirement for referral}

The complementary exams used for assessing the requirement for referral were as follows (Figure $2)$ : biopsy and/or surgical procedure $(n=61,47.3 \%)$ and requirement for radiographic examination $(n=13,10.1 \%)$. 


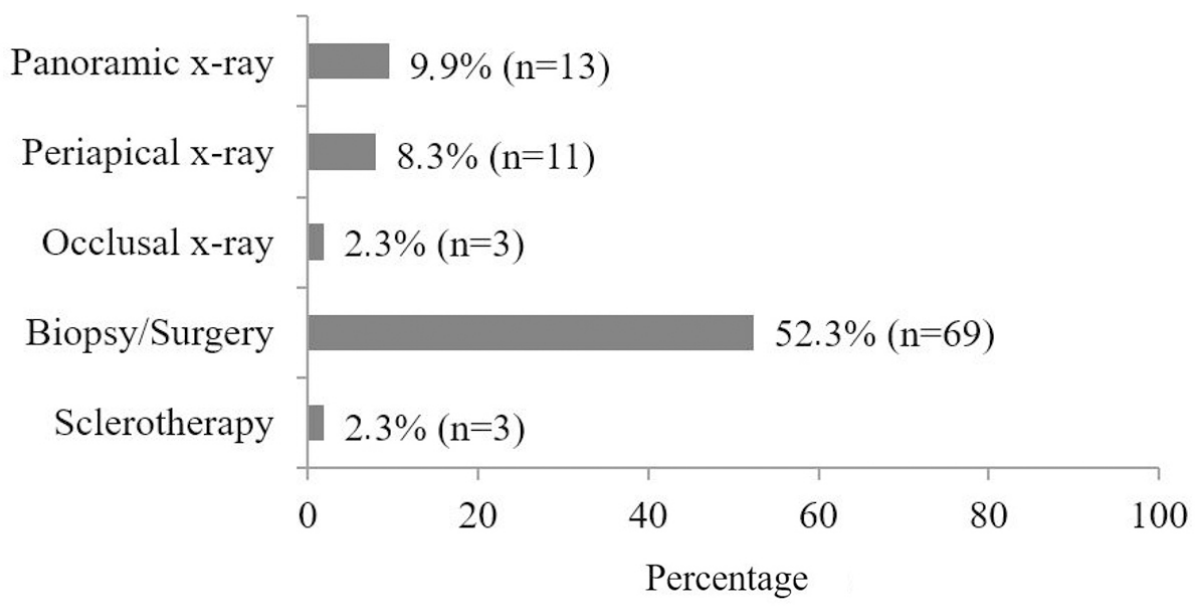

Figure 2: Complementary exams/procedures considered to define need for referral.

After analyzing the cases and considering that these resources are not available in primary care, 80 cases $(61.1 \%)$ were deemed highly complex. In addition, the following cases did not require the complementary exams mentioned above were also deemed worthy of referral because of the difficulty faced in diagnosis or treatment: lichen planus $(n=5$, $3.9 \%)$; burning mouth syndrome $(n=2,1.5 \%)$; and actinic cheilitis $(n=1,0.8 \%)$.

The analysis of the clinical diagnoses obtained from the care records showed that 51 cases $(38,9 \%)$ could have been handled in primary care. These included the following: no lesion/scar tissue, recurrent aphthous ulcerations/traumatic ulcers, candidiasis, chronic nibbling/frictional keratosis, variations from the normal pattern, bruxism, requirement for third molar extraction, tongue coating ( $n=1)$, and geographic tongue $(n=1)$.

\section{DISCUSSION}

In this study, we aimed to analyze the amount and quality of the information provided in the referral forms of patients who were referred to a service specialized in stomatology in a dental school of Brazil. In line with the findings of related studies in the literature ${ }^{22,23}$, the findings of this study confirm that referral forms has a lack of information provided by the applicant. Consequently, the services face difficulty in prioritizing the most important cases, including cases of oral cancer ${ }^{24}$. In addition, we noted that almost forty percent of the cases referred to the service in this study were not very complex and did not require sophisticated resources. This study is significant because the southern region of Brazil has a high mortality rate due to oral cancer ${ }^{25}$. Also, Brazil is one of the countries with the lowest survival rate for this disease ${ }^{25}$, and there is a lack of studies focusing on this problem.
The analysis of the completeness of the forms was based on two stages. Stage 1 focused on personal information that showed that the forms were reasonably complete, which is in accordance with the report by White et al. ${ }^{15}$. Conversely, the low frequency of the applicant's telephone number (criteria recommended by White et al., but not considered in the present analysis) represents a potential problem because that is the best form of communication between healthcare providers from different care levels $\mathrm{s}^{26}$. Chief complaint was present in approximately $50 \%$ of the referrals. This information varies considerably in the previous studies ${ }^{15,2}$ ranging from 32,2 to 98,9 . In this sense, it is important to emphasize that knowing the reason that motivates the referral for face-to-face consultation is essential for define level of priority and for the specialist's diagnostic reasoning.

Less than $50 \%$ of the referral letters had the required information to advance to Stage 2 . In this stage, the documents presented low quality in terms of lesion description (elementary lesion, color, and size), risk factors and previous treatment, reinforcing the findings observed previously ${ }^{15,22}$. Site was the most frequent information among clinical data, corroborating the findings obtained by Navarro et al. ${ }^{21}$. The lack of information on lesions' clinical appearance may be related to gaps of knowledge on oral lesions' diagnosis ${ }^{7}$. The absence of clinical impression in less than a half of the referrals also reinforces this assumption. Some reasons could be raised to explain that finding. In general, dentists do not perceive properly trained to diagnose and treat oral lesions $5,6,15,27$. Moreover, some professionals are not willing to update their knowledge on these topics ${ }^{5-8,15,28}$. Finally, some dentists assume that a full description does not contribute in the specialist evaluation ${ }^{15}$. Among those who included their clinical impression in the referral form, $73 \%$ were in accordance with the final diagnosis rendered by the specialist after full evaluation. 
Most cases correspond to non-neoplastic proliferative processes, fibroma, recurrent aphthous stomatitis/ traumatic ulcers, candidiasis and lichen planus. These findings resemble those seen in previous studies assessing cases evaluated at specialized services $^{29-31}$.

About a third of the evaluated patients had lesions that were not described in the referral letters, including candidiasis, inflammatory hyperplasia, and actinic cheilitis. However, it is not clear if the applicant had detected those lesions or undervalued them. Taking this finding into account, it should be reinforced that the dental practitioner must conduct the full oral examination, regardless the chief complaint, particularly because some high-risk lesions are painless ${ }^{32}$.

This study aimed to assess whether cases referred to specialized care were complex enough for that decision or whether they could have been managed in primary healthcare. More than $40 \%$ of the cases were easy to manage because they were resolved through drug treatment, follow-up or were part of the group of normality variations. The last group probably represented irritative lesions that regressed before the appointment with the specialist.

The other evaluated cases were considered complex, requiring procedures not available in primary healthcare, such as biopsies and surgical procedures. Nevertheless, most of these cases comprised small sized benign neoplasms and NNPP, whose diagnosis and treatment evolve a surgical procedure comparable to a tooth extraction. Hence, depending on previous training, self-efficacy and technical conditions, those cases could be feasible at primary health services. considered relatively treatable from the surgical point of view. This result can be explained by the dental surgeons' preference for referring cases like these and their insecurity in performing biopsies. This is because, among other reasons, it involves decisions regarding the ideal area from which to obtain samples, depth of incision, and amount of tissue to be collected. In this sense, dental surgeons seem to be unprepared due to lack of training during the course and difficulty in interpreting results ${ }^{5}$.

Information regarding lesion progression time is fundamental in the differential diagnosis of oral lesions because potentially malignant disorders and malignant lesions usually progress rapidly. In such cases, early diagnosis is essential for achieving a better prognosis ${ }^{24}$. More than $65 \%$ of the cases evaluated in the present study had progressed for more than two months. Although it was not possible to ascertain this time because of the retrospective nature of the study, several factors contributed to a delay in diagnosis. These include delay by the patient in seeking care ${ }^{33}$ and delays related to the professionals or the referral system ${ }^{24}$. Fortunately, the cases of potentially malignant disorders and malignant lesions in the present study had a maximum of 16 days of progression. In contrast, in seven cases the patients presented potentially malignant disorders (six cases of actinic cheilitis and one case of lichen planus) that had not been described in the referral forms.

This study had limitations inherent to a retrospective study, such as the lack of standardization in the way information is registered in care records and the impossibility of clarifying questions that arise as different documents are analyzed. In addition, because the sample was obtained from a dental school, it is not possible to extrapolate the findings and make an inference regarding dentistry specialty centers of the healthcare network.

The findings of this study showed that the large number of referrals and lack of information in the referral forms can lead to delays in appointments and, consequently, delayed diagnoses. The referral queue could be reduced if less complex cases were managed at primary care, which could become the evaluation of high risk cases (oral leukoplakia and squamous cell carcinoma, for instance) faster. This goal would be accomplished with continuing education actions, which could improve diagnostic skills, clinical decision-making skills, and communication between different levels of healthcare services. With respect to the information system, Corwin and Bolter ${ }^{14}$ suggest that the feedback provided by the specialists to the applicants could contribute toward improving the quality of referral forms, which is more effective than the implementation of electronic forms. Another strategy that has been discussed is the implementation of a template for describing lesions ${ }^{34}$. Although valid, it seems critical to adopt this strategy in view of the wide range of lesions affecting the maxillomandibular complex, as well as the difficulties perceived by professionals on lesions' description ${ }^{14}$.

Primary and secondary care professionals should collaboratively work for improving patient referral methods and, consequently, care flow at the different levels ${ }^{35}$. These issues should be a priority for health managers, as malfunctions in these flows entail unnecessary costs and compromise the quality of care. The referral forms sent to specialized centers containing information of poor quality that results in the delayed diagnoses of various diseases. Continued training, feedback provision, and collaboration among the different levels of healthcare can mitigate this problem.

\section{Note}

The presented study was presented in the 34th Brazilian Society for Dental Research in Campinas/ SP and in the 37th Scientific week of Hospital de Clínicas de Porto Alegre in Porto Alegre. Both events took place in September 2017. 


\section{REFERENCES}

1. Chandroth SV, Venugopal HK, Puthenveetil S, Jayaram A, Mathews $\mathrm{J}$, Suresh N, et al. Prevalence of oral mucosal lesions among fishermen of Kutch coast, Gujarat, India. Int Marit Health. 2014;65(4):192-8.

2. Shulman JD, Beach MM, RiveraHidalgo F. The prevalence of oral mucosal lesions in U.S. adults: data from the Third National Health and Nutrition Examination Survey, 1988-1994. J Am Dent Assoc. 2004;135(9):1279-86.

3. Mathew AL, Pai KM, Sholapurkar $A A$, Vengal $M$. The prevalence of oral mucosal lesions in patients visiting a dental school in Southern India. Indian J Dent Res. 2008;19(2):99-103.

4. MacPherson LM, McCann MF, Gibson J, Binnie VI, Stephen KW. The role of primary healthcare professionals in oral cancer prevention and detection. Br Dent J. 2003;195(5):277-81.

5. Ergun S, Ozel S, Koray M, Kürklü E, Ak G, Tanyeri H. Dentists' knowledge and opinions about oral mucosal lesions. Int J Oral Maxillofac Surg. 2009;38(12):1283-8.

6. McCann PJ, Sweeney MP, Gibson $\mathrm{J}$, Bagg J. Training in oral disease, diagnosis and treatment for medical students and doctors in the United Kingdom. Br J Oral Maxillofac Surg. 2005;43(1):61-4.

7. Diamanti N, Duxbury AJ, Ariyaratnam S, Macfarlane TV. Attitudes to biopsy procedures in general dental practice. Br Dent J. 2002(10);192:588-92.

8. Saleh A, Yang YH, Wan Abd Ghani WM, Abdullah N, Doss JG, Navonil $\mathrm{R}$, et al. Promoting oral cancer awareness and early detection using a mass media approach. Asian Pac J Cancer Prev. 2012;13(4):1217-24.

9. Brasil. Lei $n^{\circ} 8.808$, de 19 de setembro de 1990: dispõe sobre as condições para a promoção, proteção e recuperação da saúde, a organização e o funcionamento dos serviços correspondentes, e dá outras providências. Diário Oficial da União. 1990;1:18055.

10. Campos GWS, Minayo MCS, Akerman $\mathrm{M}$, Drumond M Jr, Carvalho YM, editors. Tratado de saúde coletiva. 2nd ed. São Paulo: Hucitec; 2012.

11. Mendes EV. As redes de atenção à saúde. 2nd ed. Brasília, DF: Organização Pan-Americana da Saúde; 2011.
12. Starfield B. Primary care: balancing health needs, services and technology. New York: Oxford University Press; 1998.

13. World Health Organization. Declaration of Alma Ata. International conference on primary health care, Alma-Ata, USSR, 6-12 September 1978. Geneva: WHO; 1978.

14. Corwin P, Bolter T. The effects of audit and feedback and electronic referrals on the quality of primary care referral letters. J Prim Health Care. 2014;6(4):324-7.

15. White DA, Morris AJ, Burgess L, Hamburger J, Hamburger R. Facilitators and barriers to improving the quality of referrals for potential oral cancer. Br Dent $J$. 2004;197(9):537-40.

16. Navarro CM, Onofre MA, Sposto MR. Referral letters in oral medicine: an approach for the general dental practitioner. Int J Oral Maxillofac Surg. 2001;30(5):448-51.

17. Coulter A, Noone A, Goldacre M. General practitioners' referrals to specialist outpatient clinics. I. Why general practitioners refer patients to specialist outpatient clinics. BJM. 1989;299(6694):304.

18. Jenkins RM. Quality of general practitioner referrals to outpatient departments: assessment by specialists and a general practitioner. Br J Gen Pract. 1993;43(368):111-3.

19. Mayor S. More than $90 \%$ of urgent cancer referrals seen within two weeks. BMJ. 2001;323(7313):591.

20. Bjorkeborn M, Nilsson $\mathrm{H}$, Anderud J. Quality of oral surgery referrals and how to improve them. Clin Cosmet Investig Dent. 2017;15(9):111-6.

21. Navarro CM, Miranda IA, Onofre MA, Sposto MR. Referral letters in oral medicine: standard versus nonstandard letters. Int J Oral Maxillofac Surg. 2002;31(5):537-43.

22. Ibiyemi O, Ibiyemi T. Quality and contents of referral letters from peripheral health centers to the dental centre of a teaching hospital, southwestern Nigeria. Acta Odontol Scand. 2012;70(2):165-8.
23. Onyango JF, Macharia IM. Delays in diagnosis, referral and management of head and neck cancer presenting at Kenyatta National Hospital, Nairobi. East Afr Med J. 2006;83(4):85-91.

24. Borges DM, Sena MF, Ferreira MA, Roncalli AG. Mortality for oral cancer and socioeconomic status in Brazil. Cad Saude Publica. 2009;25(2):321-7.

25. Petersen PE. Oral cancer prevention and control - the approach of the World Health Organization. Oral Oncol. 2009;45(4-5):454-60.

26. López-Jornet $P$, Camacho-Alonso $F$, Martinez-Beneyto Y, Seoane-Leston J. Influence of years of professional experience in relation to the diagnostic skill of general dental practitioners (GDPs) in identifying oral cancer and precancerous lesions. Int Dent J. 2008;58(3):127-33.

27. van Beek JH, Hoogstraten J. Dentists' opinion about their dental education from 1997 to 2004 in Amsterdam, The Netherlands. Ned Tijdschr Tandheelkd. 2006;113(10):397-400.

28. Haberland CM, Allen CM, Beck FM. Referral patterns, lesion prevalence, and patient care parameters in a clinical oral pathology practice. Oral Surg Oral Med Oral Pathol Oral Radiol Endod. 1999;87(5):583-8.

29. Farah CS, Simanovic B, Savage NW. Scope of practice, referral patterns and lesion occurrence of an oral medicine service in Australia. Oral Dis. 2008;14(4):367-75.

30. Miller CS, Hall EH, Falace DA, Jacobson JJ, Lederman DA, Segelman AE. Need and Demand for Oral Medicine Services in 1996. A report prepared by the Subcommittee on Need and Demand for Oral Medicine Services, a subcommittee of the Specialty Recognition Committee, American Academy of Oral Medicine. Oral Surg Oral Med Oral Pathol Oral Radiol Endod. 1997;84(6):630-4.

31. Silverman S Jr. Early diagnosis of oral cancer. Cancer. 1988;62(8 Suppl):1796-9.

32. Tadbir AA, Ebrahimi H, Pourshahidi $S$, Zeraatkar M. Evaluation of levels of knowledge about etiology and symptoms of oral cancer in southern Iran. Asian Pac J Cancer Prev. 2013;14(4):2217-20. 
33. Jafari $A$, Najafi SH, Moradi F, Kharazifard M, Khami M. Delay in the diagnosis and treatment of oral cancer. J Dent (Shiraz). 2013;14(3):146-50.
34. Zimmermann C, Meurer MI, Lacerda JT, Mello ALSF, Grando LJ. The use of tools to support oral lesion description in oral medicine referrals. Braz Oral Res. 2017;31:e93.
35. McCartney M, Ewart $P$, Scott $C$. Are there too many referral forms? BMJ. 2010;13(341):c6576.

Received: June 22, 2020 Accepted: May 17, 2021 